\title{
Bridging the Gap between Two Solitudes - A Review of Design Education in Mechanical Engineering and Industrial Design
}

\author{
Brian Burns† and Donald L. Russell $\ddagger$ \\ $\dagger$ School of Industrial Design \\ $\ddagger$ Department of Mechanical and Aerospace Engineering \\ Carleton University, Ottawa, Canada
}

\begin{abstract}
This paper reviews the teaching of design in the Industrial Design and Mechanical Engineering programmes at Carleton University. We summarize our approaches to design education and contrast them with the innate skills of students. Notably each curriculum puts increased emphasis on the facets of design that do not match the innate skills of the entering students. We conclude by discussing various aspects of design education as taught in the two programmes and potential mutual benefits to future design education planning.
\end{abstract}

\section{Introduction}

Within the buildings of the Faculty of Engineering and Design at Carleton University, two, apparently very different, approaches to the teaching of design can be found. This paper compares the approaches taken to design education in two different programmes within the Faculty of Engineering and Design at Carleton University in Ottawa, Canada. The mechanical engineering programme is offered by the Department of Mechanical and Aerospace Engineering and is one of twelve engineering programmes offered at Carleton University. Approximately 100 new students are admitted to the programme each year. The School of Industrial Design offers its own Bachelor of Industrial Design Degree (BID) through a four-year programme with Design studio courses forming a major component in each year. Approximately 40 students enter first year and, typically, the majority graduate four or five years later (depending on co-op and internship options). For both programs, applicant numbers are high, and the retention rate is usually very good. Currently, however, there is virtually no overlap in the courses taken by these two groups of students beyond certain math and physics in first year.

\section{Two Contrasting Design Ap- proaches}

Despite their close association both in physical location and within the university structure there is little commonality between the two programs. Both programmes (along with the other engineering programmes as well as others in the university) are concerned with design. It is evident on reviewing the two programmes that they each have a different view of design, that their students generally enter university with different basic skills and that the focus of the design education in each programme is different.

\subsection{Mechanical Engineering}

Design is integrated throughout the engineering program. The working definition of design in comes from the definition offered by the Canadian Engineering Accreditation Board[2]:

"Engineering design integrates mathematics, basic sciences, engineering sciences and comple-mentary studies in developing elements, systems and processes to meet specific needs. It is a creative, iterative and often open-ended process subject to constraints which may be governed by standards or legislation to varying degrees depending upon the discipline. These constraints may relate to 
economic, health, safety, environmental, social or other pertinent interdisciplinary factors."

Functionally, significant design content for engineering programmes in general, and the Mechanical Engineering programme at Carleton in particular, typically involves open-ended problem solving and dealing with constraints. This type of material is found, to a certain extent, in most engineering courses. The first exposure of the students to design occurs in their first engineering course. This course covers a number of topics and is taught to large classes. As a result the design material covered is usually limited in scope and the problems have limited options for creative solutions or detailed analysis. The next major course with design content is a course on graphics and design. This course focuses on computer aided drawing and contains some associated design material. This course is a recent modification of a number of courses that originally covered drafting. The extent of hand drawn work in the engineering programme has been reduced from several in-depth courses to the sketches that are used to support the computer aided drawing in the current course.

In the third year of their programme the students take a machine design course in which they, along with most mechanical engineering students, examine the detailed design of machine components. The material in this course is central to design but often runs the risk of appearing as solid mechanics and stress analysis. In the final year of the programme the major design content comes from a second machine design course that focuses more on the design of mechanical systems. A major design project, performed in structured groups of 20 to 30 students, represents the culmination of their engineering education and exposes the students to large open-ended design problems and the issues involved in working in a team to address this type of problem. Note that most other courses in the programme cover some amount of design material in the form of applications of theory that has been learned.

This pattern of design content is typical of most, but not all, mechanical engineering programs. The strength of the design content in the mechanical engineering programme at Carleton lies in the large fourth year design projects. Other programmes at other universities have their own unique strengths.

The major result of this pattern of design content is that it appears to the student primarily within the context of mathematical or theoretical analyses of other engineering topics. It is no wonder that the general reaction of an engineering student to an open-ended design problem is to reduce it as quickly as possible to a mathematical analysis. The focus of design work is not creativity or novelty but proving numerical feasibility.

The resulting designs often work or function properly to address the problem at hand. It is certainly the intent of the students to demonstrate that their ideas will work. However, little effort is put into understanding how the design might be used in practice, ideas such as ergonomics and marketability are generally on the periphery of the work (if they are considered at all). The designs may function but are not what an industrial designer would consider functional or a product. A colleague has commented that designs done by engineers are often covered in "sharp edges."

This description is, of course, a very broad overview and discounts the many excellent designs that do come from mechanical engineering students every year. The description is, however, all too applicable to the design capabilities of the average mechanical engineering student graduating from most universities.

\subsection{Industrial Design}

As its name suggests, Design is at the core of the Industrial Design programme. In general Industrial Design is globally offered in two forms; at Art and Design Schools alongside other design disciplines (fashion, graphics, furniture, textiles, jewellery etc) or based in engineering and similar technological programmes; as with the programme at Carleton University. Interestingly, graduates from both forms of programmes commonly work alongside each other in their later careers, though the programmes vary in some aspects of their technological content.

As a result of such diversity, there are many definitions of Design accepted and used in Industrial Design. Bruce Archer of the Royal College of Art in London, UK [1] offered:

"Design is a goal-seeking activity in which a model or a prescription is formulated in advance of embodiment, for an artifact that is offered as an apt and original solution to a given problem."

However, the term Industrial Design qualifies itself with a generally accepted definition proposed 
in 1971 by the International Council of Societies of Industrial Design (ICSID):

"Industrial Design is a creative activity whose aim is to determine the formal qualities of objects produced by industry. These formal qualities include the external features but are principally those structural and functional relationships that convert a system to a coherent unity both from the point of view of the producer and the user.

Industrial Design extends to embrace all aspects of the human environment that are conditioned by industrial production."

Clearly Design has many variants and many discipline specific challenges. While the bodies of knowledge may vary between disciplines, such as Engineering and Industrial Design, all require creative thinking and a respect for the issues at hand. Our challenge then is to foster and encourage appropriate levels of design creativity. Perhaps Sir Hugh Casson said it best in the 1960s when he offered:

\section{"To design is to decide"}

While students study the same mathematics and physics courses in first year as many engineering students, they also take a courses in economics and more specifically, the History of Industrial Design. However, students come into Industrial Design to design.

The first year Design Studio has a two hour lecture component together with a four hour studio session each week. Student studio sessions are conducted in groups of 20 , where students undertake a range of skill developing projects in which individual tuition and guidance is the norm. The approach tends to focus on particular skills; from perspective drawing and hand drafting to form, colour, modelling and sketching. Students are given a series of projects in which particular skills are developed with due regard to the understanding of The Design Process. All projects are thus appropriately designed to have a strong contextual component using case studies and real-life scenarios as a working backdrop.

In the winter term the students undertake a course in Industrial Design Analysis in which they study an existing product, e.g. a domestic blender, and consider its performance with regard to function, aesthetics, ergonomics, manufacture, materials, packaging, and marketing. This introduces fields of study that are taken up in specific courses in second year and beyond that become vital tools in their studio courses.

The projects build in complexity throughout the programme and generally have a team and an individual component. Projects are all open-ended though within a framework of deliverables. This means that a project can be used to highlight a particular skill or design aspect. Ultimately the final year thesis projects tend to be comprehensive and usually undertaken with a real client.

Class size is vital in all studio courses. It is expected that each student will be evaluated and given a certain amount of tuition time. While team projects can help handle larger numbers in the research phases, industrial design students tend to undertake their own individual solutions. Thus it is important that the problems have a virtually limitless range of possible solutions, and that there is time and opportunity to evaluate them. Students are expected in all projects to undertake research, analyse their findings, sketch and develop possible feasible solutions which will perhaps be tested before finalising he design. Testing has more bearing on ergonomics and manufacturing feasibility, and has only limited potential for thorough evaluation. Beyond fundamental ergonomic and manufacturing data, the solutions have little mathematical basis in their proof. Though the solution is, within the confines of the project and the instructors experience, feasible, there is still much engineering to do. All sharp edges are usually dealt with but the real product is a long way off.

This simplified overview shows a slow build of awareness in a broad range of contexts and skill sets. Success is mixed and with breadth sometimes comes a lack of depth. The hope then is to graduate an Industrial Design aware of the issues and their own abilities and limitations. Just as the driving test does not produce the perfect driver, the aim is for the graduate designer not to endanger themselves or anyone else.

\section{Comparing the Approaches}

The typical students that are attracted to each of the programmes differ in their innate abilities and academic strengths. Carletons Industrial Design students must have a good foundation in math and physics, and tend to be conceptual thinkers and 
visually oriented. They must demonstrate these skills in the portfolio part of the entrance requirements. Engineering students tend to be strong in mathematics with an analytical style of reasoning. Reasons for this separation of talent pools are numerous and include not only the attractiveness of the educational programme and the desired careers but also the opinions of parents and guidance councillors and perceptions of probable employment, stature and salary. Additionally, what might well offer a strong common-ground, Design and Technology courses are not held in high regard at most high schools and, sadly, most universities do not mention such courses in their entrance requirements.

The current pedagogical basis for each of the two programmes comes from a long history of providing appropriate skills to the students before they graduate. The differing skills and abilities of the applicant pools have an impact on the programme contents.

Engineering students typically gravitate toward solution approaches that are analytical and mathematical, shying away from creativity and conceptual work. The nature of engineering places a substantial emphasis on this type of work so, as a result, the challenge facing engineering education is to expose the students to the possibilities that come from creative and conceptual approaches to design. This is simpler when class sizes are small but current university funding schemes treat class size as a number that must be maximized for financial reasons. The resulting medium to large class sizes make the teaching a creative design much more difficult.

Industrial design students enter with solid graphical skills and continue to develop them as a natural part of their education. They, however skilled at math they might be, tend to favour conceptual based solutions over more analytical and mathematical approaches for resolving functional details within a design problem. The educational challenge here is essentially opposite to the challenge facing the engineering students in that the industrial design students need to be encouraged and mentored to focus on performing appropriate and complete analyses in support of their designs.

It is important to recall that most professors were once students in their own discipline and thus as a whole share many of the biases that are typical of the entering students. It is therefore not only a challenge to teach this material to the students but to have a pool of faculty with the appropriate skills available to teach the courses and act as mentors. Given the way that scholarly research is rewarded (and the way design activities are not rewarded) in most academic promotional schemes, it is difficult to attract these individuals. Related to this it is interesting to note that the School of Industrial Design currently has no graduate programme (plans are underway) and the focus of the faculty members is, as a result, more closely aligned with undergraduate teaching and design practice than with research.

Most engineering programmes have, in recent years, reduced the amount of drafting in their programmes (some have completely eliminated it completely). The act of drawing with pencil on paper is inherently creative even when many people draw the same object. The removal of this component from engineering education may be supportable for a number of reasons but it hampers the teaching of creative design. The joy of approaching a large blank sheet of paper (or even a napkin) with a pencil in order to solve a design problem is not something that is generally experienced as part of current engineering education. Industrial designers on the other hand have maintained a strong visual and aesthetic component to their programmes and generally include considerable drawing and drafting. However, the computer plays a far more active role after the first year of study.

\section{Discussion}

Our aim in helping to develop design in our students is to foster well-directed creativity. Faced with the diverse range of problems our students will experience in professional careers we hope that they will be able to develop well-considered responses and know when, as the adage suggests, "to think outside of the box".

In mathematics and other sciences, questions often have definitive answers, for Design the solutions may be less easy to evaluate. As new problems take us into new territory success may be more difficult to measure. Clearly, however, this does not mean that Design can be considered loose and purely subjective. The result of good Design is objective success. Clearly there are many problems that can adequately dealt with through traditional engineering practices. There, however, is a growing need for interdisciplinary work, particularly with current environmental concerns, and an even stronger need not to miss creative opportunities. While not trying to compare apples with 
oranges, in order to teach or foster good design in students, we believe there are several important factors that seem worthy of further consideration. We have listed these below in no real order of significance:

Differing Bodies of Knowledge. All disciplines are founded on a strong body of knowledge that needs to be used by specialists. It is often said that Industrial Design tends to produce generalists due to the breadth of its field of study; it can also be said that Engineering also produces generalists who go on to play a vital role in the field. At some later date, however, no matter what the discipline, specialists in differing fields need to be able to talk and work together; to speak the same language.

The nature of the challenge and the uniqueness of the solution. The design demands on a Mars Rover are far different from those of a domestic appliance. For all design challenges the levels of complexity, uniqueness, and variability must be addressed, either to assemble an appropriate design team or in matching the design challenge to the pedagogical goals.

Time availability for instruction, tuition, iteration and evaluation. By its very nature, Design is iterative; concepts must be continually formulated and tested or evaluated. While some challenges may have formulaic solutions, most design demands time with appropriate student/mentor ratios to be successful and to be learned. Industrial Design Studio courses generally recommend ratios of less than 20 to 1 to be effective. It is virtually impossible then to tackle such projects in most engineering classes. However, the fourth year design experience takes place with groups of approximately 25 students working with 5 faculty members on a large coordinated design project.

Innate talents. The entrance requirements of students, directly affects the abilities of these students to undertake design projects. Experience suggests that Industrial Designers are keen to leave the technical work to engineers, even when it could directly and adversely affect the feasibility of the product. On the other hand, some Engineers may easily jump to humorous possibilities requiring skyhooks or transparent lightweight stainless steel but are all too often forced by time and course constraints to more conservative solutions. All too frequently Engineers have little or no understanding or respect for issues of Industrial Design. Cross fertilization would seem essential; at least in awareness if not in practice.

Project costs and access to equipment. Industrial Design projects are traditionally hands-on. Workshops in wood, plastic, metal and fabric are fully utilized in testing, model making and formgiving. Students are trained and helped in using appropriate machinery, not simply in creating visual models but in openly learning and experimenting with the capabilities of materials and processes. Costs for the student in all similar design fields are considerable, and many attempts are made to minimize these costs. Such access is currently very limited and highly controlled in engineering programmes due to large class sizes and related safety concerns. It should be added that the School of Industrial Design at Carleton has to be very creative in offering appropriate safe access to such equipment to its students. Even with considerably lower numbers than in engineering access is still a concern.

Real modelmaking. We commonly see purely visual design solutions thanks to the highly capable software packages currently mastered by both engineering and industrial design students. But, as we well know, there is no such thing as a virtual lunch. Mechanical engineering can come close in some simple problems. While industrial designers often produce visually exact product models their value is largely for appearance purposes. It is vital that engineering and industrial design students be given the opportunity to learn the capabilities of materials as part of a design development process.

Team or Individual. Both engineering and industrial design have long known the importance of teamwork. Often such projects are undertaken to ease the load on the instructor, and with such practice has come creative means for individual evaluation. It would seem vital that all students should at some point be individually challenged to design.

The Question of Feasibility Mathematical models and the insertion of numbers into prescribed equations offer a degree of feasibility evaluation, but there are a considerable number of additional ways in which feasibility in industrial design and engineering can be evaluated. This range needs to be explored and respected. 
Subjectivity and Objectivity. It would seem that the more open-ended the potential solution the more likely that the evaluation would be more subjective. The unknown and often the aesthetic questions (even of comfort) can be seen to be personal and thus difficult to judge. All design projects need to have predetermined objective success criteria before being undertaken; pure science and math is not the only road to objectivity.

Comprehensive and simple projects. The design project is a learning tool. The simpler the task the more likely the simple solution. Good projects, like good math problems are developed and evolve. Industrial Design has too often felt the need to change its projects every year, and ignored pedagogical success and failure. Engineering may appear to have, all too often, retained projects too long.

Interdisciplinary Projects. Though clearly there are many difficulties encountered in establishing and evaluating inter-disciplinary projects, it would appear that such endeavors must be undertaken. Just as with the evaluation of individuals in team projects, we should develop means to evaluate success across disciplinary boundaries.

Where do industrial designers and engineers begin? It would appear that Industrial Designers are encouraged to be conceptual holistic thinkers. Bruce Archer once described one of the greatest attributes of industrial designers is to be able to "zoom in and zoom out"[1]. Faced with a design challenge, industrial designers quite naturally attempt to conceive an instant product solution, which they would attempt to refine through feasibility of function, ergonomics and manufacture. The engineering student would more likely be encouraged to focus on function, which would then be refined to be safe and reliable. Eventually they would hopefully meet in the middle.

Academics teaching Design / Designers in Academia. Most faculty entering Industrial Design teaching have considerable design experience, with several products designed, developed and marketed. That experience is quickly utilized in the studio courses, but translating those experiences to the academic courses takes more care. Engineering demands research and considerable academic success. While both disciplines might struggle with the demands of teaching, the challenge of handling design projects cannot be underestimated.

Designing Design Projects. Though students in all disciplines love to hear the instructor announce that "we are going to design a new." For those who aspire to design, nothing excites more than such a challenge. However, it is essential for the instructor to be aware of not only the pedagogical merits and time limitations, but also the likely source of the solutions, desired outcomes, and deliverables. The value of the well designed project cannot be underestimated.

\section{Closing remarks}

It would be foolish to suggest that Industrial Design and Engineering Design should become one and the same. There are differences that will remain, and rightly so. However, for cross-disciplinary challenges, for project design and management, for evaluation and mentoring, for respecting our skills and approaches we have much to learn from each other. This brief review would suggest that this is not only a wise path, but ultimately a very fruitful one.

\section{References}

[1] Archer, L. Bruce, Design Awareness and Planned Creativity in Industry, Design Council of Great Britain, London, 1974

[2] - , Accreditation Criteria and Procedures, Canadian Engineering Accreditation Board, 2005, available online at http://www.ccpe.ca/e/files/report_ceab.pdf 